\title{
Split thickness buccal mucous membrane grafts and $\beta$ irradiation in the treatment of recurrent pterygium
}

Jennifer Forbes, Richard Collin, John Dart

\begin{abstract}
Background-Pterygium is a common problem and after surgical removal may recur in up to $80 \%$ of cases, depending on the technique of primary excision. Recurrent pterygia can be aggressive and repeated excision may result in severe conjunctival scarring and shortening, resulting in insufficient conjunctiva to perform further grafting and lid surgery. When there is insufficient autologous conjunctiva, mucous membrane must be obtained from other sites. Full thickness buccal mucous membrane grafts have been described, but they may result in a beefy red appearance, with graft contraction and a poor tear film.

Method-The use of split thickness buccal mucous membrane grafts is described in three patients with recurrent pterygium, two in combination with lamellar keratoplasty. $\beta$ Irradiation was used as adjuvant therapy in all cases.

Results-In all three cases an acceptable cosmetic appearance was achieved, with no recurrence of the pterygium, and a good range of eye movements.

Conclusions-It is recommended that split thickness buccal mucosal grafts, combined with $\beta$ irradiation, should be considered in complex cases of pterygium recurrence when there is insufficient autologous conjunctiva and conjunctival shortening with restricted eye movements.

(Br f Ophthalmol 1998;82:1420-1423)
\end{abstract}

Pterygium is a commonly encountered problem and although frequently asymptomatic, may cause symptoms due to irritation, astigmatism, and reduced visual acuity which necessitate its removal. ${ }^{12}$ Current first line surgical procedures include simple excision leaving bare sclera; excision and conjunctival closure by primary anastomosis or conjunctival grafts; and excision combined with $\beta$ irradiation, mitomycin, or thiotepa..$^{1-5}$ The commonest complication is recurrence of the pterygium. The reported frequency of recurrence for primary pterygium varies widely for different procedures, ranging from $24-67 \%$ of cases after simple excision by the bare sclera technique, to $0-47 \%$ of cases after excision combined with conjunctival autografting or adjuvant therapy. ${ }^{3-13}$

Recurrences may grow aggressively, rapidly reaching and even overtaking the size of the original pterygium. Many different techniques have been suggested for dealing with recurrent pterygia, including excision combined with lamellar keratoplasty, autologous conjunctival grafts, $\beta$ irradiation, and antimitotics such as mitomycin C, 5-fluorouracil, and thiotepa, resulting in further recurrence of the pterygium in up to $30 \%$ of such cases. ${ }^{346911-15}$

Cases of repeated recurrence may develop severe conjunctival scarring and shortening, resulting in insufficient conjunctiva to perform further grafting and lid surgery, and restricted eye movements. Patients from tropical countries may also have trachomatous scarring and xerosis, which reduces the amount of conjunctiva available for autologous grafting. ${ }^{16}$ Under these circumstances, mucous membrane must be obtained from other sites. Full thickness buccal mucous membrane grafts are commonly used to reconstruct the fornices or orbital sockets in cases of severe conjunctival contracture, by plastic and adnexal surgeons. ${ }^{17}{ }^{18}$ However there are few records of buccal mucous membrane grafts in pterygium surgery and most of these are over 20 years old. ${ }^{16-23}$ More recently Fine, ${ }^{6}$ and Dash and Boparai $^{9}$ have described the use of full thickness buccal mucous membrane grafts in pterygium surgery but some authors have actively disparaged the technique. ${ }^{91124}$

The use of split thickness buccal mucous membrane has advantages over full thickness grafts, resulting in a better cosmetic appearance, and possibly less contraction. To our knowledge, the use of split thickness buccal mucous membrane has not been previously described for the management of pterygium. We present three case reports of patients who had repeated surgery for pterygium, and who eventually had split thickness buccal mucous membrane grafting combined with $\beta$ irradiation with good results. In two cases, lamellar keratoplasty was also performed.

\section{Method}

All patients were attending Moorfields Eye Hospital and surgery was performed under general anaesthesia. They all had severe recurrent pterygia with limitation of extraocular movements, and insufficient conjunctiva in either eye to permit a conjunctival flap or graft. If the cornea was sufficiently thick, a split thickness buccal mucous membrane graft was used on its own, but if previous surgery had resulted in corneal thinning, a lamellar keratoplasty was also performed. 
TECHNIQUE

Areas of conjunctival shortening and symblepharon were divided, and fibrous adhesions were released. The pterygium was excised by lamellar dissection from the cornea, and freed from normal conjunctiva and underlying sclera and recti muscles. In the two cases where the remaining cornea was very thin a trephine was used to define this area, and surrounding normal tissue, including limbus and sclera. A corneoscleral lamellar keratectomy was excised in this area and replaced with a lamellar corneal donor graft, which was sutured in place with $10 / 0$ nylon interrupted sutures. The rectus muscle was exposed further and any remaining fibrous tissue and pterygium were removed. An $0.2 \mathrm{~mm}$ split thickness mucous membrane graft was taken from the patient's lower lip with a mucotome (Aesculap microtome) and sutured to the sclera and adjacent conjunctiva with $7 / 0$ Vicryl. A conformer ring was inserted and subconjunctival injections of cefuroxime and Betnesol (betamethasone) were given. The postoperative management included removal of the ring between 4 and 12 weeks, the use of topical antibiotics until the epithelium was intact, and topical steroids until the inflammation had subsided, usually after several weeks. All patients had adjunctive $\beta$ irradiation (two applications of $750 \mathrm{cGy}$ with a 7 day interval), starting 1-35 days after surgery. This was applied to the limbal region over the cornea, the corneal graft if present, and the buccal mucous membrane graft.

\section{Results}

CASE 1

A 41 year old man had bilateral pterygia excisions with left $\beta$ irradiation in Bangladesh. He presented to Moorfields Eye Hospital in 1985, with a recurrent right nasal pterygium, and a left temporal pterygium. The right pterygium was re-excised with a conjunctival autograft in 1991, but recurred 3 months later. This pterygium has not recurred following further excision and $\beta$ irradiation. In 1986 the left pterygium was excised, leaving a bare area of sclera. After 3 months it recurred, with tethering and symblepharon to the lateral lower lid, leading to progressive restriction of abduction of the left eye due to the conjunctival shortening and symblepharon (Fig 1). Owing to the previous surgery, there was insufficient conjunctiva for an autologous conjunctival graft and in 1992 a split thickness mucous membrane graft and corneoscleral lamellar graft were performed, followed by $\beta$ irradiation with strontium-90 1 month later $(750 \mathrm{cGy} \times 2)$. Three years after surgery he has had three episodes of discomfort and redness, which have settled with topical steroids. There has been some vascular ingrowth along the graft interface, but there has been no recurrence (Fig 2). $\mathrm{He}$ achieves $6 / 9$ vision in that eye, with no restriction of movement.

CASE 2

A 58 year old African man presented in 1989 with a 4 year history of pterygium in his left eye. This was excised twice by a bare sclera

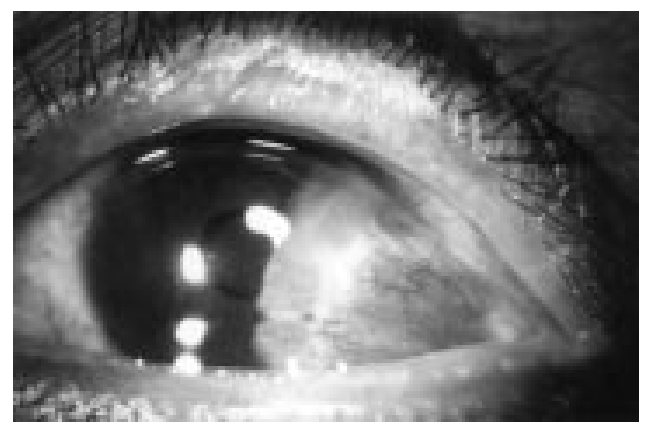

Figure 1 Case 1, before surgery, showing the extensive recurrent temporal pterygium and symblepharon in the left eye.

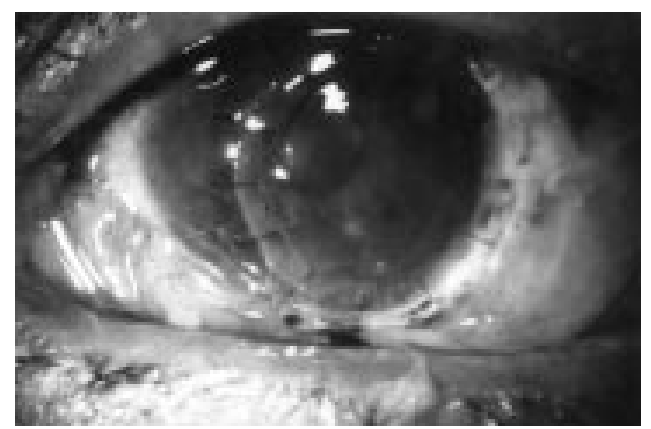

Figure 2 Case 1, after surgery to the left eye, showing the lamellar keratoplasty and buccal mucous membrane graft.

technique, but recurred rapidly both times, causing dragging of the caruncle and restriction of left abduction to $10-20 \%$ of normal. In 1991 the recurrence was excised by lamellar dissection, and a conjunctival autograft was taken from the superior fornix. One week postoperatively symblepharon had already formed between the conjunctival graft and the tarsal surface of the upper lid. These were divided with a glass rod but persisted, and by June 1991 the patient was complaining of diplopia and ptosis of the left eyelid. He developed a left/alternating divergent squint, with limitation of the left eye in adduction and abduction, and marked retraction of the globe. The recurrent pterygium had formed a thickened fleshy mass of tissue nasally, which was adherent to the upper lid, forming a symblepharon from the limbus to the superior border of the tarsus. The patient also had open angle glaucoma and it was felt preferable to leave the remaining conjunctiva undisturbed in case he should require future glaucoma surgery (which has since been performed). The patient underwent a corneoscleral lamellar graft and split thickness buccal mucous membrane graft, followed by $\beta$ irradiation 2 weeks later $(750 \mathrm{cGy} \times 2)$. $\mathrm{He}$ made a good recovery from the surgery, apart from one episode of pain and photophobia, which settled on topical dexamethasone $0.1 \%$. At 5 years after the operation, the lamellar graft was clear, with a left visual acuity of $6 / 9$, and there was no recurrence of the pterygium.

CASE 3

A 55 year old sailor was referred from Falmouth with a long history of bilateral pterygia, having undergone four excisions on the 


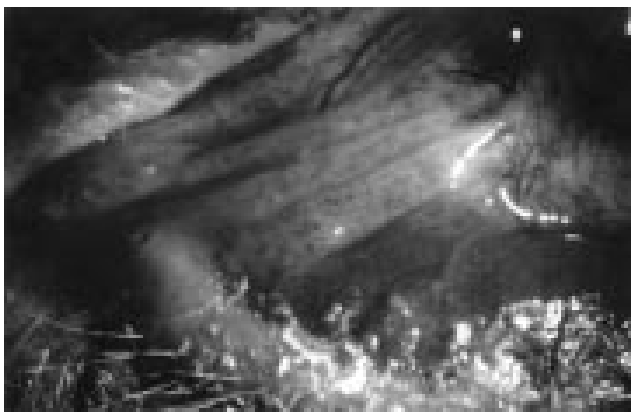

Figure 3 Case 3, before surgery, showing the recurrent pterygium and the severe symblepharon to the left lower eyelid.

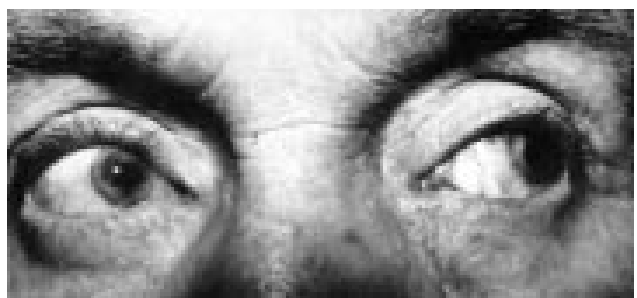

Figure 4 Case 3, after left split thickness buccal mucous membrane grafting, showing the improved appearance and good range of eye movement.

right, and five procedures on the left side. $\mathrm{He}$ had not had a mucous membrane graft or irradiation. On presentation the right eye had a recurrent pterygium, but no lid deformities. The pterygium on the left side had been buried in the inferior conjunctiva at the last procedure but already showed recurrence with active corneal invasion. It had developed a large symblepharon to the medial end of the lower lid, resulting in a marked ectropion, with an irregular lid contour, limitation of abduction, and ulceration and keratinisation of the tarsal conjunctiva, causing symptoms of crusting and lacrimation (Fig 3). The multiple previous operations with the resultant severe conjunctival shortening restricted the amount of autologous conjunctiva available for grafting. In 1990 he underwent a wide excision of the left pterygium, with a split thickness mucous membrane graft from the lower lip, and correction of the associated ectropion by a full thickness lid resection and everting sutures. Postoperatively he was given $\beta$ irradiation (750 cGy) on days 1 and 7 , and was put on topical dexamethasone and chloramphenicol. He has achieved a reasonable range of eye movements (Fig 4) and still has a comfortable, white eye with no recurrence of the pterygium or the symblepharon 7 years later.

\section{Discussion}

Barraquer proposed that pterygium occurs because of localised discontinuity of the precorneal lacrimal film, but current theories implicate ultraviolet light damage, and other stimuli may contribute to the degenerative process. ${ }^{25-27}$ The rate of recurrence after the initial pterygium excision varies from $0 \%$ to $67 \%$, depending on the technique used. ${ }^{5-7}$ Potential risk factors for recurrence include younger patients with aggressive pterygia, aggressive postoperative inflammatory reac- tion, and re-exposure to sunlight, and outdoor occupations. $^{2581026-29}$ However, recurrences usually appear within months, which cannot be explained simply by re-exposure to ultraviolet light. The underlying mechanism of recurrence is not fully understood and there have been several theories suggested in the literature, including immunological, neoplastic, and reparative mechanisms. ${ }^{528-32}$

Simple excision is not effective at preventing regrowth and most methods aim to provide a barrier to the regrowth of the abnormal tissue, with restoration of the normal limbal architecture and tear film, using conjunctival autografts, lamellar keratoplasty, mucous membrane from other sources such as the mouth, or non-mucosal grafts-for example, skin. ${ }^{324} 33{ }^{34}$ Conjunctival grafting to discourage regrowth is recommended, and may be taken as an ipsilateral pedicle, or free graft, or as free patch grafts from the contralateral eye. ${ }^{12} 1824$ Antimitotic agents or irradiation may be used to discourage the regrowth of pterygia by inhibiting fibroblast proliferation, and possibly inflammatory cells. ${ }^{24}$

The cases presented here had aggressive recurrences of their pterygia after repeated conventional surgical procedures, resulting in severe conjunctival scarring and shortening, with symblepharon formation and restriction of their eye movements. There was insufficient normal conjunctiva remaining to perform further conjunctival grafting and lid surgery, and in one case the remaining conjunctiva had to be preserved in case of future glaucoma surgery. Lamellar keratoplasty was required in two cases because there was marked thinning and scarring of the cornea following repeated lamellar dissection.

Buccal mucosal membrane grafts are commonly used to reconstruct the fornices or orbital sockets by plastics and adnexal surgeons but their use is rare in pterygium surgery nowadays. ${ }^{6}{ }^{17}$ Full thickness buccal mucous membrane grafts were originally used for recurrent pterygium by Klein in 1876, and the technique has been described in the literature for both primary and recurrent pterygium. $^{6} 161920-2335$

The advantages of buccal mucosa are that it is in plentiful supply when there is a shortage of conjunctiva, and can be combined with irradiation therapy. It provides a mucous membrane covering, which may act as a barrier to regrowth. Trivedi et al claim to have had no recurrences in their series, and Fine also found no recurrences in 22 cases. ${ }^{6}{ }^{16}$ Calabre and colleagues reported recurrences in $6.2 \%$ of cases. ${ }^{23}$ Fine recommends the technique as "a very valuable procedure in the most vascular, aggressive recurrences with limitation of motility and symblepharon". ${ }^{6}$ The disadvantages of the technique are that the full thickness grafts may develop a beefy red appearance which is highly visible, and they may develop contraction with subepithelial fibrosis, scarring, and shrinkage. ${ }^{9} 1924$ Split thickness mucous membrane grafts provide a much better cosmetic appearance than a full thickness graft. Failure of the buccal mucosal epithelium to transform 
into normal conjunctival and corneal epithelial cells may also result in functional difficulties involving surface wetting and the tear film, but this was not apparent in our cases, who have achieved good ocular comfort. ${ }^{24}$ The use of split thickness buccal mucosa in our cases has resulted in an acceptable cosmetic appearance, and the patients have attained a good range of eye movements, without recurrence of the pterygium.

The use of autologous conjunctival mucous membrane is generally recommended in cases of recurrent pterygia, or in other conditions of conjunctival scarring such as alkali burns, or symblepharon. ${ }^{18} 24$ However, buccal mucous membrane provides an alternative source of mucous membrane when there is insufficient conjunctiva available in either eye. We have obtained good results using this technique in these complicated cases, although a recurrence rate for this technique cannot be established from this small series. We recommend that split thickness buccal mucosal grafts in conjunction with $\beta$ irradiation should be considered in complex cases of pterygium recurrence when there is a lack of autologous conjunctiva, and associated conjunctival shortening and restricted eye movements.

We wish to acknowledge the help of David Bessant in gathering the references, and Jane Walker for organising the photographs of case 3 .

1 Vorkas AP. Pterygium. Choice of operation. Trans Ophthalmol Soc UK 1981;101:192-4.

2 Demartini DR, Vastine DW. Pterygium. In: RL Abbott, ed. Surgical intervention in corneal and external diseases. Orlando, USA: Grune and Stratton, 1987:141-53.

3 Pearlman G, Susal AL, Hushaw J, et al. Recurrent pterygium and treatment with lamellar keratoplasty with presentation of a technique to limit recurrences. Ann $O p h$ thalmol 1970;2:763-71.

4 Manning CA, Kloess PM, Diaz MD, et al. Intraoperative mitomycin in primary pterygium excision. Ophthalmology 1997;104:844-8

5 Zauberman H. Pterygium and its recurrence. $A m$ f Ophthalmol 1967;63:1780-6.

6 Fine M. Recurrent pterygium: mucous membrane grafts. Symposium on Medical and Surgical Diseases of the Cornea. St Louis. Transactions of the New Orleans Academy of Ophthalmology 1980:533-40.

7 de Kaiser RJ, Swart-van den Berg M, Baartse WJ. Results of pterygium excision with Sr 90 irradiation, lamellar keratopterygium excision with Sr 90 irradiation, lamellar kerato-
plasty and conjunctival flaps. Doc Ophthalmol 1987;67:33plasty

8 Kaimbo K Surgical treatment of pterygium: 24 cases of excision. F Fr Ophtalmol 1988;11:335-8.
9 Dash RG, Boparai MS. Pterygium-evaluation of management (primary and recurrent). Indian $\mathcal{f}$ Ophthalmol ment (primar

10 Lewallen S. A randomised trial of conjunctival autografting for pterygium in the tropics. Ophthalmology 1989;96:16124.

11 Dowlut MS, Laflamme MY. Recurrent pterygia: frequency and treatment by conjunctival autograft. Can $\mathcal{F}$ Ophthalmol 1981;16:119-20.

12 Kenyon KR, Wagoner MD, Hettinger ME. Conjunctival autograft transplantation for advanced and recurrent pterygium. Ophthalmology 1985;92:1461-70.

13 Poirier RH, Fish JR. Lamellar keratoplasty for recurrent pterygium. Ophthalmic Surg 1976;7:38-41.

14 Laughrea PA, Arentsen JJ. Lamellar keratoplasty in the management of recurrent pterygium. Ophthalmic Surg $1986 ; 17: 106-8$

15 Mohan M, Panda A, Goyal JL. Surgical management of recurrent pterygium (Mohans technique). In: The cornea: transactions of the World Congress on the Cornea III, ed. Dwight Cavanagh. New York: Raven Press, 1988:377-81.

16 Trivedi LK, Massey DB, Rohatgi R. Management of pterygium and its recurrence by grafting with mucous membrane from the mouth. Am $\mathcal{F}$ Ophthalmol 1969;68: 355-6.

17 Putterman AM, Scott R. Deep ocular socket reconstruction. Arch Ophthalmol 1977;95:1221-28.

18 Thoft RA. Conjunctival transplantation. Arch Ophthalmol 1977;95:1425-7.

19 Gifford $H$. The treatment of recurrent pterygium. Ophthalmic Rec 1909;18:1-8.

20 Denig RCR. Transplantation of mucous membrane of mouth for various diseases and burns of the cornea. $N Y$ Med F 1918;107:1074-5.

21 Duverger C. Extirpation du pterygion et greffe de muqueuse buccale. Arch Ophthalmol 1926;43:704-8.

22 Green J. Mucous membrane transplant in recurrent pterygium. Am f Ophthalmol 1937;20:942.

23 Calabre C, Fantin J, Bondier JM, et al. Interet de la greffe de muqueuse buccale dans la traitment du pterygion. [Value of the buccal mucous graft in the treatment of pterygium.] Bull Soc Ophtalmol Fr 1978;78:493-5.

24 Vastine DW, Stewart WB, Schwab IR. Reconstruction of the periocular mucous membrane by autologous conjunctival transplantation. Ophthalmology 1982;89:1072-81.

25 Barraquer MJI. La discontinuite localisee du film lacrymal precorneen. Ophthalmologica 1965;150:111-22.

26 Taylor H. Aetiology of climatic droplet keratopathy and pterygium. Br F Ophthalmol 1980;64:154-63.

27 Mackenzie FD, Hirst LW, Battistutta D, et al. Risk analysis in the development of pterygia. Ophthalmology 1992;99: 1056-61.

28 Youngson RM. Recurrence of pterygium after excision. $\mathrm{Br} \mathcal{F}$ Ophthalmol 1972;56:120.

29 Doherty WB. A discussion of pterygia and a report of a new technique for their removal. Am f Ophthalmol 1941;24: 790-4.

30 D'Ombrain A. Surgical treatment of pterygium. $\mathrm{Br} \mathcal{F}$ Ophthalmol 1948;33:65.

$31 \mathrm{McG}$ avic JS. Surgical treatment of recurrent pterygium. Arch Ophthalmol 1949;42:726-48.

32 Paton D. Pterygium management based upon a theory of pathogenesis. Trans Am Acad Ophthalmol Otol 1975;79:603.

33 Reeh MJ. Corneoscleral lamellar transplant for recurrent pterygium. Arch Ophthalmol 1971;86:296-7.

34 Wong WW. Behaviour of skin grafts in the treatment of recurrent pterygium. Ann Ophthalmol 1977;9:352-6.

35 Klein: Zur Operation des Pterygium und zur Transplantation von Scheimhaut. Allgem Weiner Med Zeitung 1876;3-4. (Quoted in Rosenthal JW. Chronology of pterygium therapy. Am f Ophthalmol 1953;36:1601-16.) 